\title{
DIMENSÃO NOÉTICA: AS CONTRIBUIÇÕES DA LOGOTERAPIA PARA A COMPREENSÃO DO SER HUMANO
}

\section{NOOLOGICAL DIMENSION: THE CONTRIBUTIONS OF LOGOTHERAPY FOR UNDERSTANDING THE HUMAN BEING}

\section{DIMENSIÓN NOÉTICA: LAS CONTRIBUCIONES DE LA LOGOTERAPIA PARA LA COMPRENSIÓN DEL SER HUMANO}

\author{
Larissa Fernanda Dittrich ${ }^{1}$ \\ Marcelo Felipe Leite Oliveira ${ }^{2}$
}

\begin{abstract}
RESUMO: Esta pesquisa tratou do tema "Dimensão noética: as contribuições da logoterapia para a compreensão de ser humano". Para Frankl, o ser humano é entendido como uma unidade tridimensional constituída por instância biológica ou factual, psicológica ou anímica e noética ou espiritual, sendo esta última o princípio distintivo da espécie, elemento primordial da constituição humana, fonte da liberdade e responsabilidade, bem como da busca por sentido e da autotranscendência culminando, assim, na autorrealização. O objetivo geral desta pesquisa foi compreender a dimensão noética em Viktor Frankl, sendo de cunho bibliográfico com abordagem fenomenológica, baseando-se nos conceitos da dimensão noética, de ser humano e do sentido da vida à luz da logoterapia. Investigaram-se livros, artigos científicos, teses relacionados ao objeto de estudo. A metodologia para captação e compreensão dos dados foi a hermenêutica fenomenológica. Como resultado, ficou evidenciada a visão de ser humano em Frankl como uma unidade tridimensional, composta pela relação dialógica, recíproca e interdependente das dimensões biológica, psicológica e espiritual, em que uma abarca a anterior, em um movimento de suprassunção. Essa tríade condensa-se em um "vir-a-ser" humano, tendo o espírito como instância superior dessa totalidade. Por fim,compreendeu-se a dimensão noética ou espiritual como instância fundadora do sentido para a vida.
\end{abstract}

PALAVRAS-CHAVE: Dimensão noética, Sentido de vida, Ser humano.

ABSTRACT: The theme of this study is the "Noological dimension: the contributions of logotherapy for understanding the human being". For Frankl, the human being is understood as a three-dimensional unit consisting of: a biological or factual dimension, a

Licença CC BY:

Artigo distribuído sob os termos Creative

Commons, permite uso e distribuição irrestrita em qualquer meio desde que o autor credite a fonte original. psychological or emotional dimension, and a noological or spiritual dimension, the latter being the main distinguishing feature of the species and a primordial element in the human constitution, a source of freedom and responsibility, and of the search for meaning and

\footnotetext{
1 Professora do Curso de Psicologia UNIVALI.

2 Acadêmico do Curso de Psicologia UNIVALI.
} 
self-transcendence, culminating in self-realization. The general objective of this research was to understand the noological dimension in Viktor Frankl. This is a bibliographical study with a phenomenological approach, based on the concepts of the noological dimension, human being, and the meaning of life in light of logotherapy. It investigates books, scientific articles, and theses related to the object of study. The methodology used to collect and understand the data was phenomenological hermeneutics. As a result, the vision of the human being in Frankl was seen as a three-dimensional unit, composed of a dialogic, reciprocal and interdependent relationship between the biological, psychological and spiritual dimensions, in which each takes in the one precedes it, in a movement of suprasumption. This triad is condensed into a human "becoming", with the spirit as the higher instance of this totality. Finally, it understands the noological or spiritual dimension as a founding instance of meaning of life.

KEYWORDS: Noological dimension, Meaning of life, Human being.

RESUMEN: Esta investigación trató del tema "Dimensión noética: las contribuciones de la logoterapia para la comprensión del ser humano”. Para Frankl, el ser humano es entendido como una unidad tridimensional constituida por instancia biológica o factual, psicológica o anímica y noética o espiritual, siendo esta última el principio distintivo de la especie, elemento primordial de la constitución humana, fuente de la libertad y responsabilidad, bien como de la búsqueda por sentido y de la autotrascendencia culminando, así, en la autorrealización. El objetivo general de esta investigación fue comprender la dimensión noética en Viktor Frankl, siendo de cuño bibliográfico con abordaje fenomenológico, basándose en los conceptos de la dimensión noética, del ser humano y del sentido de la vida a la luz de la logoterapia. Se investigaron libros, artículos científicos, tesis relacionadas al objeto del estudio. La metodología para captación y comprensión de los datos fue la hermenéutica fenomenológica. Como resultado, quedo evidenciado la visión del ser humano en Frankl como una unidad tridimensional, compuesta por la relación dialógica, recíproca e interdependiente de las dimensiones biológicas, psicológicas y espirituales, en que una abarca a la otra, en un movimiento de supersunción. Esta tríade se condensa en un "venir a ser" humano, teniendo el espíritu como instancia superior de esta totalidad. Por fin, se comprendió la dimensión noética o espiritual como instancia fundadora del sentido para la vida.

PALABRAS-CLAVE: Dimensión noética, Sentido de la vida, Ser humano.

\section{INTRODUÇÃO}

Desde seu nascimento a psicologia busca compreender o ser humano na sua interação consigo, com o outro e com o mundo. Para tanto, criou sistemas e elaborou teorias de cunho epistêmico/filosófico distintas, que pudessem dar respostas a questões fundamentais tais como: Quem é o ser humano? O que o diferencia das demais espécies? Ou, ainda, qual o sentido ou a razão da existência?

A psicologia moderna, como ciência, nasce nos laboratórios de Willian Wundt no final do século XIX, o qual introduziu o Método Cartesiano ${ }^{3}$ das especulações psicológicas por meio do paradigma positivista ${ }^{4}$. Parafraseando o pai da psicologia experimental: "A primeira etapa da investigação de

3 O Ceticismo Metodológico é um método que consiste em quatro etapas básicas: a) verificar as evidências reais do fenômeno estudado; b) analisar ou dividir (reduzindo) unidades de composição fundamentais e estudar da mais simples a mais complexa; c) sintetizar, ou seja, agrupar novamente as unidades estudadas em um todo; e d) enumerar as conclusões e os princípios utilizados a fim de manter a ordem lógica do pensamento (DESCARTES, 2002).

4 Alusão ao Positivismo Científico é o sistema criado por Auguste Comte (1798-1857), que se propõe a ordenar as ciências experimentais, considerando-as o modelo por excelência do conhecimento humano, em detrimento das especulações metafísicas ou teológicas (COMTE, 1983). 
um fato deve ser uma descrição dos elementos individuais [...] dos quais ele consiste" (SCHULTZ; SCHULTZ apud DIAMOND, 2016 p. 69), permitindo assim o desenvolvimento de uma ciência psicológica no sentido mais estrito da palavra, tendo em vista que até então os estudos da mente humana eram disciplinas de outras vertentes do conhecimento, tais como a filosofia e a teologia.

Não há como negar, contudo, que essa perspectiva positivista da ciência permitiu uma grande evolução na compreensão do mundo, bem como possibilitou uma verdadeira explosão de conhecimento tecnológico e científico que permitiu a humanidade chegar à lua ou mesmo dividir um átomo, além de criar vacinas e tecnologias médicas, mas, ao mesmo tempo, inventar e ser capaz de utilizar a bomba atômica. A capacidade tanto de proporcionar longevidade e qualidade de vida quanto de destruir a própria existência é fruto dessa revolução, que segundo Harari (2014, p. 257), foi promovida pela " $[\ldots]$ descoberta da ignorância $[\ldots]$ " 5 ante o mundo, abrindo espaço para a dúvida, sendo essa a base do cientificismo cartesiano, elemento fundante da ciência moderna.

Embora as técnicas de perspectiva positivista sejam de grande valia para as ciências naturais, tornam-se limitadas ou insuficientes para questões relativas às ciências humanas, por não conseguir abarcar toda a complexidade da existência (FEYERABEND, 2011). Sobre essas limitações, Olavo de Carvalho declara:

A experiência humana tomada como totalidade ilimitada é a mais básica das realidades, ao passo que o objeto de cada ciência é uma construção hipotética erigida dentro de um recorte mais ou menos convencional dessa totalidade. (CARVALHO, 2013, p. 381).

É, portanto, um erro concluir que filosofia ou mesmo a ciência opõem-se radicalmente a questões espirituais. Ao contrário, todas se tornam lentes pelas quais se pode observar o ser humano e, para uma melhor e mais completa consciência do mesmo, é necessário que o observador as sobreponham, como em um telescópio, a fim de contemplar com mais profundidade.

Viktor Emil Frankl (1905-1997) foi um médico e professor judeu, nascido em Viena, fundador da terceira escola vienense de psicoterapia, denominada de Logoterapia e Análise Existencial. Durante a Segunda Guerra Mundial teve sua teoria posta à prova em sua própria vivência como prisioneiro nos campos de concentração nazistas de Theresienstadt, Auschwitz, Dachau (Kaufering III e Türkheim), reconhecido como um dos maiores nomes da psicologia existencial humanista, sagrando-se como uma das mentes mais brilhantes do século XX (TROMBLEY, 2014).

Mas o que o destacou, dentre tantos notáveis da psicologia moderna? Para Olavo de Carvalho (2013), a teoria de Frankl sobrepõe-se às inúmeras vertentes de pensamento moderno, uma vez que propõe uma ciência pautada em uma retomada e fusão de quatro grandes áreas de estudo do ser humano: teologia; psicologia/psiquiatria; antropologia e filosofia, que por pelo menos trezentos anos haviam sido consideradas quase que antagônicas6, tendo em vista que o cientificismo, notadamente cético, vigente no final dos séculos XIX e início do XX, acaba por reduzir os fenômenos e as experiências espirituais ou transcendentes a meras crendices e superstições de

5 Descoberta da ignorância é o termo utilizado pelo autor para definir a condição humana de busca e anseio pela verdade quando se depara com o não saber, caracterizado no desenvolvimento tecnológico e nas descobertas científicas que permeiam a história da espécie (HARARI, 2014).

6 O termo antagônico se refere à Revolução Científica iniciada por Nicolau Copérnico e Galileu Galilei no século XVI, a qual promoveu uma cisão entre ciência (razão) e fé (espiritualidade), tendo em vista que ambas se arrogavam como detentoras da "verdade", opondo-se drasticamente uma a outra. (FEYERABEND, 2011; HARARI, 2014 KOYRÉ, 2006). Frankl (2007), por sua vez, de maneira brilhante, utilizando da antropologia e da filosofia, promove um resgate da espiritualidade humana para o debate científico, uma vez que concebe o ser humano como sendo um ser biopsicoespiritual. 
caráter místico, deixando-as de fora da especulação científica. Ainda sobre a obra de Viktor Frankl, Carvalho afirma:

Num século que tudo fez para deprimir o valor da consciência humana, para reduzi-la a um epifenômeno de causas sociais, biológicas, linguísticas, etc., Frankl nadou na contracorrente e ninguém conseguiu detê-lo. Ninguém: nem os guardas do campo nem as hostes inumeráveis de seus antípodas intelectuais - os inimigos da consciência. Frankl apostou no sentido da vida e na força cognoscitiva da mente individual. Apostou nos dois azarões do páreo filosófico do século XX [...] Apostou e venceu. (CARVALHO, 2013, p. 49).

Cabe ressaltar que a psicologia, a antropologia, a teologia e a filosofia são matérias imbricadas e complementares. Com a modernidade e a lógica cartesiana, foram separadas, descaracterizando, assim, o ser humano com um ser completo, uma vez que cada disciplina estuda uma dimensão humana. Mas Frankl vem novamente unificar esse ser humano biopsicoespiritual. Sobre o assunto, Frankl afirma que o fio condutor que atravessa todas as obras é a luta contra as tendências despersonalizadoras e desumanizantes que partem do Psicologismo em Psicoterapia (FRANKL, 2010).

De cunho existencial-fenomenológico, a teoria de Frankl contempla o ser humano como uma unidade tridimensional: a) a dimensão somática ou biológica, relativa aos fenômenos corporais e da materialidade; b) a dimensão psicológica ou anímica, contemplando instintos, condicionamentos e cognições; e c) a dimensão no ética, referente à “[ ...] pessoa espiritual profunda [...]” (FRANKL, 2007 p. 14) ou à espiritualidade inconsciente presente no ser humano, sendo essa a fonte do sentido da vida, uma vez que é na dimensão noética que se encontram as respostas às perguntas filosóficas mencionadas anteriormente (FRANKL, 2007).

Concebendo o indivíduo como um ser livre e responsável (FRANKL, 2007), a Logoterapia embasa sua teoria em quatro conceitos filosóficos básicos: a pessoa, a liberdade, a responsabilidade e o significado ou sentido. É precisamente a dimensão noética que torna o trabalho de Frankl tão importante para a psicologia, uma vez que o autor se coloca na contramão do Zeitgeist $t^{7}$ e das vertentes teóricas científicas de viés positivista e ateísta, bem como ao Materialismo Histórico ${ }^{8}$ vigentes em sua época, trazendo novamente a espiritualidade para as especulações psicológicas, não mais como mero resultado cultural, ilusão religiosa ou superstição, mas como elemento central e primário da própria constituição humana (CARVALHO, 2013). A esse respeito ele afirma:

Uma psicologia [...] que se orienta pelo modelo metodológico das ciências naturais, se comprometem com uma falsificação, com uma desnaturalização, e com uma desumanização do sujeito humano, na medida em que este sujeito, submetido à observação, se transforma, inevitável em objeto. (FRANKL, 1990, p. 35).

Frente ao exposto, o tema desta pesquisa é: "Dimensão Noética: as contribuições da Logoterapia para a compreensão do ser humano”, tendo como problema: O que é o ser humano em sua dimensão noética para Viktor Frankl?

7 Zeitgeist: termo alemão que significa “espírito da época”. Segundo Schultz e Schultz (2016, p. 98), trata-se das "[...] ideias predominantes na ciência e cultura da época [...] ou o clima intelectual da época [...]".

8 Corrente histórica e filosófica de análise socioeconômica criada por Karl Marx (1818-1883) e Friedrich Engels (1820-1895), que compreende o ser humano como fruto das condições materiais de vida, figuradas nos meios de produção, trabalho e nas lutas de classes, elementos esses que determinam a consciência humana (MARX; ENGELS, 2007). 
A presente pesquisa é relevante tanto para acadêmicos quanto para a comunidade em geral, devido à importância que a compreensão do ser humano tem no contexto das ciências sociais e humanas, uma vez que em meio a uma sociedade cada vez mais alienante, despersonalizadora e líquida, a teoria de Viktor Frankl nunca foi tão atual e necessária, justamente por resgatar a autenticidade, a liberdade e a responsabilidade da existência humana, manifesto no sentido que o indivíduo dá a sua vida.

O objetivo geral desta pesquisa é compreender a dimensão noética em Frankl. São objetivos específicos: conceituar o ser humano na visão de Frankl e apresentar a dimensão noética como instância fundante do sentido da vida.

\section{COMPREENSÃO DE SER HUMANO EM FRANKL}

Para Frankl, o ser humano é orgânico em sua estrutura, psicossocial em seu desenvolvimento, mas essencial e primariamente espiritual em sua existência, compreendendo-o como uma unidade composta, afirmando que "O homem é efetivamente uma unidade e uma totalidade corpóreopsíquico-espiritual” (FRANKL, 2012, p. 62). Essa perspectiva é a base de sua ontologia dimensional, opondo-se ao niilismo presente nas perspectivas reducionistas, uma vez que, para ele, a existência é um fenômeno primário e irredutível, impossível de ser compreendida totalmente (FRANKL, 1976).

Ainda sobre esse assunto, Frankl (2011) afirma:

[...] a ontologia dimensional está longe de resolver o problema mente-corpo. No entanto, ela explica porque tal questão não pode ser solucionada. Inevitavelmente, a unidade do ser humano- unidade essa apesar da multiplicidade do corpo e da mente - não pode ser achada em suas faces psicológica, nem biológica, mas deve ser procurada em sua dimensão noológica na qual o homem foi de início projetado. (FRANKL, 2011 , p. 36).

Sobre a pessoa, Frankl (2011) a compreende como um indivíduo não somente no sentido estrito da palavra (in-dividuum), “unidade”, mas também (in-summabile), “totalidade”, e como tal não é passível de subdivisão ou cisão alguma, porque ela é uma unidade tridimensional, biopsicoespiritual, sendo cada uma das instâncias interdependentes e indivisíveis.

Reiterado por Peter (1999) a respeito da compreensão humana de Frankl, afirma:

[...] a dimensão somática, a psíquica e a noética tornam-se ontologicamente diversas, porém antropologicamente inseparáveis, na medida em que a dimensão superior (a noética) unifica e agrupa em torno do próprio núcleo a globalidade do ser humano. (PETER, 1999, p.38).

O termo biopsicoespiritual, cunhado por Frankl (2007), compreende as instâncias da constituição do ser: biológica, anímica e espiritual. Cabe, contudo, ressaltar que essa classificação é meramente didática, uma vez que, para o autor, “[...] a existência humana é unitas multiplex" (FRANKL, 2012), podendo ser experienciada somente na unicidade do ser, ou seja, em sua tríade unitária, reafirmando, assim, a premissa aristotélica de que totalidade é maior que a mera soma das partes (ARISTÓTELES, 2006). 
Ainda a respeito da constituição biopsicoespiritual, Hahnemann (1995) afirma:

[...] a força vital de natureza espiritual (autocracia), que dinamicamente anima o corpo material (organismo), reina com poder ilimitado e mantém todas as suas partes em admirável atividade harmônica, nas suas sensações e funções, de maneira que o espírito dotado de razão, que reside em nós, pode livremente dispor desse instrumento vivo e são para atender aos mais altos fins de nossa existência. (HAHNEMANN, 1995, p. 27).

Em uma alusão à mitologia grega, Frankl denomina os complexos condicionantes da liberdade humana de destino (Schicksal), que em suas palavras é “ $[\ldots .$.$] aquilo sobre o que não temos influência,$ aquilo que essencialmente escapa ao poder de nossa vontade” (FRANKL, 2011, p. 95), sendo três esses destinos: o psíquico figurado no instinto e no caráter; o biológico, representado no corpo e na hereditariedade; e sociológico, por meio do ambiente físico e social (FRANKL, 2003, pp. 125-137). A esse respeito, Frankl afirma:

As três modalidades mencionadas de niilismo não devem ser confundidas com a fisiologia, a psicologia e a sociologia. Ao contrário, o ‘ismo’ começa justamente quando o ângulo de visão de uma camada se amplia até chegar a constituir uma visão do mundo, ou seja, quando tem início a generalização. A psicologia, a fisiologia e a sociologia erram ao generalizar. Reduzindo tudo acabam tornando tudo relativo, com uma exceção: absolutizam a si mesmas. (FRANKL, 1978, pp. 187-188).

Frankl coloca-se como opositor não das ciências como instrumento de estudo e investigação, nem mesmo do Método Cartesiano, fundamental para a sistematização do conhecimento, mas dos "ismos" propagados pelas compreensões absolutistas, que reduzem o ser a meros epifenômenos de fantasias sexuais reprimidas, projeções de poder ou ainda resultado de imposições genéticas e sociais.

Esse movimento é denominado pelo autor como pandeterminismo, que é a “[ [...] visão do ser humano que descarta a sua capacidade de tomar uma posição frente a condicionantes quaisquer que sejam” (FRANKL, 2008, p. 153), caracterizado por ele como uma máscara do niilismo e solo fértil sobre o qual o reducionismo floresce (FRANKL, 2011 ), sendo caracterizado por desumanizar e desapropriar o indivíduo de suas mais distintivas características: a liberdade e a responsabilidade ante sua própria existência, tornando, assim, a vida sem sentido.

Ainda sobre sua oposição aos sistemas de pensamento excessivamente cientificistas, Frankl faz uma contundente crítica ao sistema ideológico absolutista de viés cientificista, ao afirmar:

Não foram apenas alguns ministérios de Berlim que inventaram as câmaras de gás de Maidanek, Auschwitz, Treblinka: elas foram preparadas nos escritórios e salas de aula de cientistas e filósofos niilistas, entre os quais se contavam e contam alguns pensadores anglo-saxônicos laureados com o Prêmio Nobel. É que, se a vida humana não passa do insignificante produto acidental de umas moléculas de proteína, pouco importa que um psicopata seja eliminado como inútil e que ao psicopata se acrescentem mais uns quantos povos inferiores: tudo isto não é senão raciocínio lógico e consequente. Mas a eutanásia só se tornou lógica e consequente quando o homem passou a ser cínico e niilista. (FRANKL, 2003, p. 45).

Nesse sentido, o constructo teórico de Frankl não nega as concepções dualistas, biologicistas, racionalistas, empiristas, socioculturais, teológicas ou ainda as psicoterapias anteriores ${ }^{9}$. A esse

$9 \quad$ As psicoterapias anteriores se referem às duas escolas de psicoterapias vienenses anteriores à logoterapia: a psicanálise de Freud e a psicologia individual de Adler. (FIZZOTI, 2014). 
respeito o autor afirma que sua teoria “[ [...] não quer é suplantar as psicoterapias anteriores: quer somente chegar mais alto, agregar-lhes algo” (FRANKL, 1991, p. 121), objetivando uma visão holística da experiência humana, ou seja, o ser humano não é um espírito, tampouco um fenômeno social, somático ou psíquico, e sim um ser vivenciando a sua própria existência em todas as dimensões possíveis, sejam elas espiritual-sócio-cultural-biológica e psicológica (FRANKL, 2011 ).

A respeito de sua visão holística e integradora do ser humano em contraste às perspectivas cientificistas e cartesianas, Frankl afirma:

O homúnculo moderno não é gerado em grutas e alambiques, mas lá onde expomos o homem como um autômato reflexivo ou um feixe pulsional, como um joguete de reações e instintos, como um produto de pulsões, herança e mundo circundante. Em uma palavra: onde retiramos consequências biologistas de resultados de pesquisas biológicas, de resultados de pesquisas psicológicas e psicologistas etc. A partir da biologia é bem fácil ver surgir biologismo mas de uma teoria homunculística nunca pode resultar uma práxis humanista. (FRANKL, 2014, p. 58-59).

Assim, rejeitando a concepção de que o ser humano é uma mera vítima indefesa dos fatalismos do destino, joguete das pulsões instintivas, relações de poder ou resultado de um contexto social, familiar e cultural perverso. Frankl concebe, assim, o ser humano, embora condicionado em sua condição psicofísica, um ser eminentemente livre e dono de seu destino, único em sua existência, por ser responsável, criativo, moral e tendo a condição de se transcender.

\section{DIMENSÃO BIOLÓGICA}

Sobre a dimensão biológica ou factual, Frankl (1978) afirma que é a instância mais superficial e animal do ser, apresentando-se como o elemento material da vida, uma vez que está condicionada a fatores ambientais e genéticos ou como o autor define: "destino biológico" (FRANKL, 2003, p. 125), os quais estão condensados no corpo físico, o "ser-aî”.

Corroborando com esse conceito, pode-se afirmar que o ser humano, assim como os demais seres vivos, possui uma classificação taxonômica biológica, o qual é classificado como um primata bípede do género Homo, subespécie sapiens (PAPAVERO,1994). Essa dimensão somática ou biológica é caracterizada pela factualidade orgânica compartilhada com todos os demais animais e de cunho eminentemente hereditário. Segundo a Síntese Evolutiva (ARAÚJO, 2006), é resultado de um processo de constante evolução, seleção natural e de auto-organização (KAUFFMAN, 1997).

Nesse sentido, pode-se ainda afirmar que em termos estritamente biológicos, o ser humano não é o mais apto da natureza. Ao contrário, é, na verdade, um dos animais fracos e fisicamente mais desfavoráveis ante as demais espécies do planeta (MATURANA; VARELA, 1995). Mas como esse ser tão desfavorecido fisicamente ante as demais espécies pode em um tempo relativamente curto, do ponto de vista evolutivo, passar de acanhado e pequeno grupo de caçador coletor habitante de cavernas para os senhores do planeta, ousando ainda aventurar-se fora dele?

A resposta para Frankl é a dimensão noética, por ser fonte da consciência moral, da responsabilidade e do sentido; esse, por sua vez, culmina na possibilidade de transcendência do elemento distintivo do ser humano ante as demais espécies. Reiterado por Paulo Kroeff (2011), citando Lukas, Frankl e Navarro (1983): 
A logoterapia, portanto, substitui a fórmula niilista de que o homem 'é somente' (um animal mais evoluído, um produto do acaso...) pela fórmula positiva de que o homem é "muito mais do que...". (KROEFF apud LUKAS; FRANKL; NAVARRO, 1983 p. 52).

Referindo-se à constituição do ser humano na esfera factual, Dittrich reitera a presença de uma rede de sistemas psicossomáticos, afirmando:

[...] biologicamente, acontece dentro de uma rede psicossomática, nos seus diversos sistemas endócrino, nervoso, imunológico e circulatório. No entanto, esta complexidade sistêmica somática é condição biofísica para que o ser humano possa sentir, pensar e agir [...]. (DITTRICH, 2008 p. 91).

Frankl, embora não trate profundamente em seus escritos desta dimensão, não a ignora, uma vez que essa, além de constituir o "todo humano", é ainda a instância em que o indivíduo experiencia o mundo material e é porta de entrada de muitas de suas vivências em uma relação íntima e dialética com a dimensão anímica, uma vez que os processos psicológicos básicos as inter-relacionam.

\section{DIMENSÃO PSICOLÓGICA}

Sobre a dimensão psicológica ou anímica, Frankl afirma que, “[ [...] além de herdado através da disposição genética é ainda plasmado pela educação” (1978, p.131), é a esfera mediadora entre a factualidade biológica e a interioridade genuína e absoluta do espiritual, uma vez que exerce uma relação dialética entre ambas. Refere-se às questões simbólicas e aos fenômenos psíquicos, sendo ainda a instância em que se manifestam os transtornos mentais. A esse respeito, Frankl afirma:

O homem de hoje, ao contrário do que ocorria nos tempos de Sigmund Freud, já não é sexualmente frustrado, mas existencialmente frustrado. E hoje sofre menos do que no tempo de Alfred Adler, de um sentimento de inferioridade do que de um sentimento de falta de sentido, precedido por um sentimento de vazio, de um vazio existencial. (FRANKL, 1991, p. 155).

Em sua teoria, Frankl rompe com as concepções psicologistas vigentes na época e seus antigos mestres, afirmando que o que move o ser humano não é a vontade de poder de Adler, nem o princípio do prazer de Freud, mas sim a vontade de sentido, sendo essa vontade o motor propulsor da existência humana, uma vez que a frustração existencial é a fonte primária de sofrimento para Frankl (1991). A esse respeito declara:

Enquanto a psicanálise vê o neurótico só de um lado, como dominado pelo princípio do prazer, ou seja, a vontade orientada ao prazer, e a psicologia individual como determinado pelo afã de prestígio, ou seja, a vontade de poder, a nova psicoterapia vê também a vontade orientada ao sentido. (FRANKL, 1991, p. 120).

Para ambos os sistemas (Psicologia Individual e Psicanálise), o ser humano é entendido como impulsionado ou ainda determinado tanto pelo desejo quanto pela vontade de poder, caracterizando, assim, um “[ ...] automatismo do aparelho psíquico [...]” (FRANKL, 2007, p.16). Esse determinismo psíquico apresenta-se na obra freudiana pelas referências da mitologia grega, nas quais os personagens não podem fugir de seu destino já traçado por forças cósmicas (FREUD, 2006). Opondo-se a esse pensamento, Frankl traz a compreensão que o ser humano é livre e capaz 
de distanciar-se dos condicionantes biológicos e psíquicos por meio de sua instância mais profunda e autêntica, a noética (FRANKL, 2012).

Sobre a relação entre o psicofísico e a dimensão noética, Frankl afirma:

A relação entre a pessoa espiritual e o organismo somático é instrumental. O espírito instrumenta o psicofísico, ele o forma para si na medida em que o faz utensílio, órgão, instrumentum. A pessoa espiritual comporta-se em relação ao seu organismo de modo análogo ao músico em relação ao seu instrumento. (FRANKL, 1978, p.117).

Para Frankl, o homem não é livre das condições biopsicossociais, mas sim para escolher as atitudes que toma perante tais condições (FRANKL, 2012). Em suas palavras: “[ ...] à condicionalidade factual do homem se deve contrapor sua incondicionalidade facultativa” (FRANKL, 1978, p. 70), a fim de promover a escolha e com ela a liberdade. A esse respeito Frankl ainda afirma: “[ ...] a vida humana não significa nunca viver factualmente e sim, sempre, viver facultativamente!” (FRANKL, 1991, p. 214).

Segundo Xausa (1988, p. 94), a teoria frankliana não compreende o ser humano “[ [...] como encerrado pelos influxos deterministas de sua natureza biopsicológica [...]”, ao contrário, é propriamente humano, surge no exato momento em que o ser deixa de ser determinado. Sobre isso Frankl ainda afirma: "O ser humano propriamente dito começa onde deixa de ser impelido, e cessa quando deixa de ser responsável” (FRANKL 2007, p. 19).

Sobre a noodinâmica, movimento de significação da própria existência, pelo qual o ser humano busca o sentido da vida, o autor afirma:

O ser humano precisa não de homeostase, mas daquilo que chamo de "noodinâmica" [...]. Ouso dizer que nada no mundo contribui tão efetivamente para a sobrevivência, mesmo nas piores condições, como saber que a vida da gente tem um sentido. Há muita sabedoria nas palavras de Nietzsche: "Quem tem um por que viver pode suportar quase qualquer como”. (FRANKL, 2008, p.130).

Para Frankl, a noodinâmica é precisamente o que move e impulsiona o ser humano, trazendo para ele a responsabilidade por dar o sentido da sua existência, tornando-o livre para fazer suas escolhas, característica exclusiva da constituição ontológica humana.

\section{DIMENSÃO NOÉTICA}

Para Frankl, assim como nas demais perspectivas científicas e psicológicas, o ser humano é constituído de uma instância biológica (factual) e psicológica (anímica) como os outros animais. Mas se essa similaridade é absoluta, por que a prevalência da espécie humana sobre as demais? Se não, o que o difere? As respostas de Frankl para essas perguntas é precisamente a dimensão espiritual ou noética, sendo esta “[ ...] instância abissal [...]” (FRANKL, 2007, p. 30), primária e genuinamente humana, fonte da subjetividade, valores, criatividade, liberdade, consciência moral

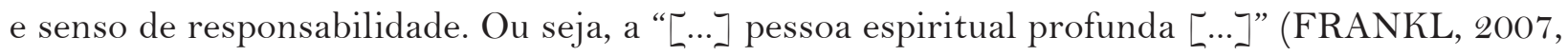
p. 39), mas para compreendermos a dimensão noética, é necessário primeiramente entender o que é espírito para Frankl. 
O que nós compreendemos como dimensão noológica se refere a uma conceituação antropológica, muito mais do que teológica. O mesmo também vale para o 'logos', no contexto do termo 'logoterapia'. Além de denotar 'sentido', 'logos' aqui significa 'espírito' - mas, novamente, sem qualquer conotação religiosa primária. Aqui, 'logos’ significa a humanidade do ser humano e o sentido de ser humano! (FRANKL, 2011, p. 17).

Etimologicamente o termo espiritual vem do grego nô̂s, que remete a questões essencialmente humanas, como: intelecto, racionalidade, ética, sentido e valores (FRANKL, 2003), em uma retomada dos conceitos clássicos da filosofia grega de pessoa como um ser espiritual (ARISTÓTELES, 2006; PLATÃO, 2001). Já em termos antropológicos, Frankl toma da compreensão de Max Scheler (2003, p. 45), que concebe o espírito como sendo “[...] por si incapaz de ser objetivado - ele é pura atualidade, só tem seu ser na livre realização de seus atos. O centro do espírito, a pessoa”. Portanto, espírito na visão frankliana é a própria essência do ser humano, uma vez que ele é a fonte primária do ato, a consciência pura (FRANKL, 2003).

Cabe, contudo, destacar que o constructo frankliano de dimensão noética refere-se a uma conceituação antropológica e não teológica ou ainda religiosa,10 de cunho confessional, uma vez que o autor compreende que a religiosidade “[...] só é genuína quando existencial, quando a pessoa não é impelida para ela, mas se decide por ela [...] espontaneamente” (FRANKL, 2007, p. 69).

Premissa essa reafirmada por Herman Dooyeweerd (1984). O espiritual, para Frankl, vai além do sacro ou do supranatural, visto que, embora o autor não ignore esses fenômenos, os compreende como resultantes e não causa primária da espiritualidade humana, assim como “[...] as decisões pessoais de vontade, intencionalidade, interesse prático e artístico, pensamento criativo, religiosidade, senso ético e compreensão do valor [...]” (LUKAS, 1989, p. 29), elementos vivenciados exclusivamente na existência humana (FRANKL, 2011). Conceito corroborado por Guedes e Gaudêncio:

É nessa dimensão espiritual que se localiza a tomada de posição, em face das condições corporais e de existência psíquica, além das decisões pessoais de vontade, intencionalidade, interesse prático e artístico, criatividade, senso ético e a compreensão do valor. (GUEDES; GAUDÊNCIO, 2012).

A dimensão noética para Frankl é a essência fundante da espécie humana, distinguindo-a das demais, uma vez que os animais são condicionados e reflexos, já o ser humano é livre e responsável. Sobre esse assunto, Frankl afirma:

Homem e animais são constituídos por uma dimensão biológica, uma dimensão psicológica e uma dimensão social, contudo, o homem se difere deles porque faz parte de seu ser a dimensão noética. Em nenhum momento o homem deixa as demais dimensões, mas a essência de sua existência está na dimensão espiritual. (FRANKL, 2003, p.34)

Frankl atribui ao ser humano uma essência primariamente espiritual, pautada não somente por racionalidade, trabalho, meios de produção ou ainda por questões semânticas, como defendido por outras teorias. Mas a real distinção entre o ser humano e as demais espécies consiste em

10 Embora o autor tivesse sua espiritualidade pautada em uma religião, o judaísmo, a teoria de Frankl não é um tratado teológico de cunho confessional, uma vez que ele não destaca uma religião ou caminho específico para Deus. A logoterapia foca apenas no caráter transcendental da experiência humana e não no religioso (FRANKL, 2007). 
sua natureza espiritual, manifesta na liberdade, na responsabilidade, nos valores e pela busca do sentido da vida. Embora primordial, a dimensão noética é, em certo sentido, inconsciente ${ }^{11}$. Sobre esse assunto Frankl afirma:

O inconsciente não se compõe unicamente de elementos instintivos, mas também espirituais. Desta forma o conteúdo do inconsciente fica consideravelmente ampliado, diferenciando-se em instintividade inconsciente e espiritualidade inconsciente. (FRANKL, 2007, p 32).

Como dito anteriormente, a visão frankliana da constituição humana é caracterizada, sobretudo, por uma unidade composta pela relação dialógica recíproca e interdependente das três instâncias já citadas, em que uma abarca a anterior, em um movimento de suprassunção ${ }^{12}$, na qual “[ [...] dimensão inferior é, portanto, 'elevada' à dimensão superior, exatamente no sentido plúrimo que Hegel confere a este termo” (FRANKL, 2003, p. 46). Essa tríade condensa-se em um "vir-a-ser” humano, tendo o espírito como instância superior dessa totalidade. A esse respeito, Frankl afirma:

Nenhuma unidade psicossomática no homem, por mais íntima que seja, consegue constituir sua totalidade; a essa última pertence essencialmente o noético, o espiritual, porque o homem representa um ser, certamente não só espiritual, mas sim em sua essência e porque a dimensão espiritual é constitutiva para ele, enquanto esta representa a dimensão, certamente não a única, mas sim a específica, de sua existência, quer se considere o espiritual no homem de maneira fenomenológica, como sua personalidade, quer de maneira antropológica, como sua existencialidade. (FRANKL, 1995, p. 66).

Frankl define seu projeto terapêutico como uma “[ [...] psicoterapia em termos espirituais" (FRANKL, 2003, p.17). A respeito da construção teórica frankliana, essa é caracterizada por uma perspectiva integradora e holística do ser humano, uma vez que sua ontologia dimensional propõe uma leitura mais abrangente da existência, não ignorando um dos mais, senão o mais, característico fenômeno humano, a espiritualidade.

Lukas, uma de suas mais proeminentes discípulas, afirma:

[...] Frankl desenvolveu sua própria antropologia, cuja afirmação central é a seguinte: o homem possui uma dimensão existencial, que o distingue dos outros seres vivos e para qual não se transferem as ocorrências da esfera bio-psíquica. Frankl denominou-a então dimensão noética (da palavra grega nous, espirito). A partir de então, suas pesquisas concentram-se em tornar fecunda essa dimensão espiritual do homem, com o fim de aliviar e superar as perturbações da alma. (LUKAS, 2005, p. 146).

Sobre a existência, Frankl ainda afirma que é uma experiência espiritual, tendo em vista que, $a$ priori, é por meio da dimensão noética que se significa toda a vivência psicofísica humana. Em outras palavras, por meio da dimensão noética, instrumentalizando as demais, em um movimento de suprassunção, a vida adquire sentido para quem a vive. Sobre isso Frankl afirma:

11 Há de se destacar a diferença entre o inconsciente espiritual de Frankl e o inconsciente instintivo de Freud, uma vez que Frankl não limita o ser humano a impulsos de natureza libidinal. Embora o autor não desconsidere a teoria Freudiana, a amplia considerando a dimensão noética como uma instância anterior, mais profunda e irrefletida do ser (FRANKL, 2007).

12 O termo suprassunção, em alemão Aufhebung, é o conceito fundamental da dialética de hegeliana, caracterizado por um movimento do espírito humano de superação, aniquilação e conservação da natureza material ou exterioridade (HEGEL, 1992). 
Assim, a existência propriamente humana é existência espiritual. Neste sentido, a dimensão noética é considerada superior às demais, sendo também mais compreensiva porque inclui as dimensões inferiores, sem negá-las - o que garante a totalidade do homem. (FRANKL, 2003, p.34).

Frankl ainda afirma que "O conceito de homem da logoterapia está baseado em três pilares, a liberdade da vontade, a vontade de sentido, e o sentido da vida” (FRANKL, 2011, p. 16). Conceito reiterado por Peter (1999), ao afirmar que a antropologia frankliana pressupõe o ser humano como um ser eminentemente espiritual (espiritual-pessoal), livre (autodeterminado), dotado de valores (responsável), esses valores o impulsionam à busca de sentido e com isso pode transcender-se.

Sobre o primeiro pilar, a liberdade, ante a experiência humana da existência, o indivíduo se depara com a condição de protagonista da sua vida, condenado à liberdade (SARTRE, 1987), possuindo o poder de decisão, que traz consigo a questão da consciência e uma vez "[ $\ldots .$.$] A liberdade pode$ corromper-se em mera arbitrariedade, a menos que seja vivida nos termos de uma responsabilidade" (FRANKL, 2011, p. 66).

Esse binômio, liberdade-responsabilidade, é uma característica exclusivamente humana. Ou seja, “o ser-eu significa ser-consciente e ser-responsável” (FRANKL, 2012, p. 10), fonte tanto de prazer quanto de sofrimento, declarando que “[ [... Assim sendo, a logoterapia vê na responsabilidade (responsibleness) a essência propriamente dita da existência humana” (FRANKL, 201 1, p. 12). Ainda sobre esse assunto, Kroeff (2011), citando Frankl, afirma:

[...] a consciência e a responsabilidade constituem precisamente os dois fatos fundamentais da existência humana. O qual, traduzido numa forma antropológica fundamental, podia expressar-se assim: ser-homem equivale a ser-consciente-eresponsável (...) são os dois aspectos juntos e combinados que oferecem a imagem total e verdadeira do homem. (KROEFF apud FRANKL, 1967, p. 13).

A respeito da autotranscendência, Frankl compreende que a existência não é um fim em si, limitada a uma constante busca por prazer, poder e prestígio ou ainda fadada a condicionamentos biopsicossociais; ao contrário, transborda e abre-se ao mundo de maneira que o “[ [...] ser humano sempre aponta e se dirige para algo ou alguém diferente de si mesmo - seja um sentido a realizar ou outro ser humano a encontrar" (FRANKL, 2008, p. 135). Ou seja, quanto mais fora de si, dedicado a uma causa ou alguém, mais livre, autêntico e, consequentemente, mais humano, sendo precisamente esse o movimento de encontro do sentido da vida (FRANKL, 2011). Frankl, sobre esse aspecto, destaca:

A autotranscedência assinala o fato antropológico fundamental de que a existência do homem sempre se refere a alguma coisa que não ela mesma $\square$ a algo ou a alguém, isto é, a um objetivo a ser alcançado ou à existência de outra pessoa que ele encontre. Na verdade, o homem só se torna homem e só é completamente ele mesmo quando fica absorvido pela dedicação a uma tarefa, quando se esquece de si mesmo no serviço a uma causa, ou no amor a uma outra pessoa. É como o olho, que só pode cumprir sua função de ver o mundo enquanto não vê a si próprio. (FRANKL, 1991, p. 18).

Com isso, pode-se afirmar que, para Frankl, o objetivo da vida não é a autorrealização e, sim a autotranscendência, uma vez que não é um fim em si mesma, apresentando-se como o caminho em direção ao próprio sentido da vida, que se manifesta em um trabalho a realizar ou no encontro com o outro (amor) ou, ainda, no sofrimento inerente à existência. 
Sobre o segundo pilar, vontade de sentido, Frankl o define como o desejo mais primordial do ser humano, caracterizado pela busca contínua de sentido na existência. Ou ainda, em suas próprias palavras, “[ [...] o esforço mais básico do homem na direção de encontrar e realizar sentidos e propósitos” (FRANKL, 201 1, p. 50), sendo este o motor impulsionante do indivíduo, caracterizado pela busca da autotranscendência.

Quando essa energia propulsora é frustrada ou ainda quando essa tensão perde potência, o ser humano sofre com o vácuo ou com a frustração existencial, fonte primária de todo o sofrimento psíquico existencial, manifesto, entre outros sintomas, segundo Frankl (2012), em abuso de drogas, disfunções sexuais, consumismo, depressão e suicídio (FRANKL, 2003). A esse respeito, Frankl afirma: “[ ...] este sentimento [...] é potencialmente patogênico” (FRANKL, 2008, p. 164), podendo dar origem a neuroses noogênicas.

Sobre o último pilar da base teórica frankliana, sentido da vida e sua íntima relação com a dimensão noética, tratar-se-á mais detalhadamente a seguir.

\section{DIMENSÃO NOÉTICA E SENTIDO DA VIDA}

Frankl compreende o ser humano como um ser eminentemente espiritual e em uma constante busca por sentido. Mas como identificar ou ainda cumprir o sentido da vida? Nesse sentido, Frankl (2008, p. 138) afirma “ $[\ldots .$.$] podemos descobrir este sentido na vida de três diferentes formas: 1. criando um$ trabalho ou praticando um ato; 2. experimentando algo ou encontrando alguém; 3. pela atitude que tomamos em relação ao sofrimento inevitável”, essa noodinâmica é manifesta em valores.

O primeiro são os valores criadores (ativos), manifesto mediante o sentido que se dá ao trabalho e o potencial criador de cada indivíduo por meio de uma tarefa em um movimento de dar-se ao mundo. Trabalho, nesse sentido, não diz respeito ao quanto o ser humano pode produzir, mas como o faz, tendo em vista a criatividade, o altruísmo, a dedicação e a realização, os quais são mais importantes em termos existenciais do que os resultados econômicos.

Enquanto os valores criadores ou a sua realização ocupam o primeiro plano da missão da vida $[\ldots]$ Em particular, o trabalho pode representar o campo em que o caráter com a comunidade, recebendo assim seu sentido e o seu valor. Contudo este sentido e valor é inerente em cada caso, à realização (à realização com que se contribui para a comunidade) e não a profissão concreta como tal. (FRANKL, 2003, p. 160).

Frankl apresenta os valores criadores como que representações objetivas dos fenômenos subjetivos, uma vez que o ser humano só é capaz de produzir algo ou realizar um trabalho condizente com sua própria condição espiritual, sendo a vida no sentido mais amplo possível, a própria manifestação da obra da pessoa. Como afirma Frankl:

Escrever um livro não é uma grande coisa, saber viver é muito mais e ainda mais é escrever um livro que ensine a viver. Mas o máximo é viver uma vida sobre a qual se possa escrever um livro. (FRANKL, 2010, p. 9).

O segundo são os valores vivenciais, que, segundo Frankl (2003), são caracterizados pelos encontros intersubjetivos e nas vivências, em que se pode contemplar “[ [...] a bondade, a verdade e a beleza, experimentando a natureza e a cultura ou, ainda, experimentando outro ser humano em sua originalidade própria - amando-o” (FRANKL, 2008, p. 136). É precisamente nesse movimento 
de se abrir ao mundo e aos outros para receber que, para Frankl, o amor se apresenta. Cabe, contudo, destacar que o conceito frankliano de amor pouco tem a ver com romantismo ou ainda satisfação sexual, embora ambos sejam expressões do amor.

Ainda a respeito do amor, Frankl (2008, p. 136) afirma que “[...] é a única maneira de captar outro ser humano no íntimo da sua personalidade”. E ainda contemplar no outro o que está “[ [...] potencialmente contido nele, aquilo que ainda não está, mas deveria ser realizado [...]”, ou seja, ver na pessoa do amado o que ela pode vir a ser.

Finalmente, os valores de atitude se manifestam mediante a perplexidade e a brevidade da vida, na lida com o sofrimento em um movimento em que o ser espiritual (noético) realiza-se, sendo intencionalmente dirigido para algo ou para alguém além de si próprio, a transcendência ante o sofrimento inevitável. Sobre isso, Frankl argumenta:

Só quando o homem já não tem nenhuma possibilidade de realizar valores criadores; só quando ele já não está realmente em condições de configurar seu destino, só então pode realizar os valores de atitude; só nessa altura tem algum sentido "carregar a sua cruz". A essência de um valor de atitude reside precisamente no modo como um homem se submete ao irremediável. (FRANKL, 2003 p.155).

A proposta de Frankl com relação ao sofrimento, uma vez que inevitável, é transformá-lo, ressignificando-o em sacrifício por meio do sentido que se dá ao sofrer, atribuindo-lhe uma visão positiva, em suas palavras " $[\ldots .$.$] se é que a vida tem sentido, também o sofrimento necessariamente$ o terá” (FRANKL, 2008, p. 67). A respeito de sua própria vida e obra, Frankl (2008, p. 170) afirma que “[ .... s sem o sofrimento, o crescimento que atingi teria sido impossível”.

Com isso se pode afirmar que o sofrimento, para Frankl, “[ ...] não significa apenas esforçar-se, crescer e amadurecer, mas igualmente enriquecer-se” (FRANKL, 1978, p. 241), pois ao encarar a dor, o ser humano pode transcendê-la por meio do sentido atribuído, assim, dando-a um caráter positivo, transformando-a em sacrifício. A esse respeito Frankl ainda afirma que "O sacrifício é capaz de dotar de sentido até a morte, enquanto o instinto de conservação, por exemplo, não consegue sequer dar um sentido à vida” (1978, p. 245). Contudo, cabe ressaltar que “[ ...] o sofrimento não é de modo algum necessário para encontrar sentido. Insisto apenas que o sentido é possível mesmo a despeito do sofrimento [...]” (FRANKL, 2008, p. 78).

Pode-se com isso afirmar que o sentido da vida para Frankl está precisamente no constante movimento (noodinâmica) de entregar-se a um trabalho ou tarefa, deslocar-se de si mesmo, abrindo-se ao mundo e ao outro, ou ainda no movimento de encarar o sofrimento inevitável da existência com dignidade. Nota-se ainda que o sentido da vida para Frankl não é único, estático ou rígido, pois a cada dia a vida apresenta-se com novas e diversas situações e cabe ao indivíduo responder a vida de acordo com a altura das situações a ele apresentadas, ressignificando sua própria existência por meio da consciência (Gewissen) e intencionalidade. Nesse sentido, afirma:

O que é, então, um ser humano? É o ser que sempre decide o que ele é. É o ser que inventou as câmaras de gás; mas é também aquele ser que entrou nas câmaras de gás, ereto, com uma oração nos lábios. (FRANKL, 2008, p. 112).

Nesse sentido, a dimensão noética apresenta-se como catalizadora e decodificadora dos fenômenos figurados nas instâncias anteriores em uma busca constante do sentido, por meio da consciência que, segundo o autor, “[ [...] é o órgão do sentido, é a capacidade de descobrir o sentido único e 
irreprodutível que se esconde em cada situação” (FRANKL, 1978, p. 19). Essa noodinâmica é o movimento de resposta constante, atual e autêntica à existência materializada em seus valores.

\section{METODOLOGIA}

A pesquisa “Dimensão noética: as contribuições da logoterapia para a compreensão do ser humano", teórica, de cunho epistemológico, estruturou-se a partir de um olhar hermenêutico fenomenológico. Na estruturação do referencial central no processo hermenêutico, usaram-se autores como Viktor Emil Frankl, Elisabeth Lukas, Olavo de Carvalho e Izar Xausa para os conceitos de ser humano, do sentido de vida e da dimensão noética.

A hermenêutica, como um método filosófico, abre a possibilidade de entrar no conhecimento das teorias e dos saberes e percorrer caminhos, muitas vezes, velados para se descobrir novos conceitos que nascem de novas reflexões na pesquisa. Apresentando a fenomenologia como uma abordagem filosófica, que defende que na pesquisa a produção do conhecimento se dá na síntese entre pesquisador e objeto, Fragata (1965) observa que o pesquisador conhece, na medida em que ele mesmo, sujeito cognoscente, vive pela e na sua consciência o seu objeto.

Diante disso, a compreensão do objeto desta pesquisa seguiu o seguinte processo hermenêutico:

1. Indutivamente, fez-se o levantamento de referências em algumas das obras dos autores supracitados.

2. Intencionalmente, escolheram-se e organizaram-se os dados que colaboram para as reflexões, com base nas categorias pertinentes ao objeto de pesquisa.

3. Perceptivamente, o pesquisador, no processo de indução-dedução, fez reflexões, problematizações e registros explicativos, utilizando categorias conceituais para trazer respostas ao problema de pesquisa.

4. Ao final, apresentou-se a compreensão final dos dados teóricos, que remetem às considerações finais na descrição dos resultados alcançados.

\section{CONSIDERAÇÕES FINAIS}

Viktor Emil Frankl foi grande nas três esferas em que se pode medir um ser humano: na inteligência, na coragem e no amor ao próximo (CARVALHO, 2013), manifestos em sua brilhante articulação teórico filosófica, base de seu modelo psicoterapêutico e na dignidade com que enfrentou seu destino como prisioneiro dos campos de concentração nazistas durante a Segunda Guerra Mundial. Em outras palavras, um homem à altura de sua própria teoria e esta de valor inestimável para a humanidade.

Se, por um lado, Frankl opôs-se às tendências niilistas e despersonalizadoras das ciências humanas em sua época, sua teoria é atual e relevante para a sociedade pós-moderna, cada vez mais líquida, alienante e voltada ao consumo, soterrados por enormes fluxos de informações sem reflexão, objetivação em massa e virtualização das relações. As psicopatologias contemporâneas mais características, tais como o vazio existencial, a ansiedade, a toxicodependência, a depressão e o suicídio, têm suas mais profundas raízes na ausência de sentido da vida (FRANKL, 2011). A teoria frankliana visa resgatar esse sentido da existência do indivíduo por meio de uma retomada à sua espiritualidade, fonte primária da dignidade humana, autenticidade, responsabilidade e autotranscendência.

Frankl, em sua teoria, busca responder os três questionamentos filosóficos básicos: Quem é o ser humano? É um ser responsável, livre e exclusivo autor de sua existência. O que o diferencia 
das demais espécies? Constituído por uma unidade tridimensional, biopsicoespiritual, sendo essa última eminentemente humana, uma vez que o ser humano é o único ser capaz de refletir sobre si e transcender-se. Qual o sentido ou a razão da existência? A dimensão noética é precisamente a instância que traz sentido/razão para a vida e fundamento da própria responsabilidade do indivíduo ante a existência.

O presente trabalho teve como objetivo geral compreender a dimensão noética em Viktor Frankl, a qual é a própria "pessoa espiritual profunda”, fonte da subjetividade, valores, criatividade, liberdade, consciência moral e senso de responsabilidade.

Primeiramente, conceituou-se o ser humano na visão de Viktor Frankl como um ser que é orgânico em sua estrutura, psicossocial em seu desenvolvimento, mas essencial e primariamente espiritual em sua existência, concebendo-o como um ser único, livre, responsável, impulsionado pela vontade de sentido e capaz de autotranscender.

Conclui-se, com isso que, para Frankl, o ser humano é uma unidade tridimensional, biopsicoespiritual, sendo essa última a dimensão noética, a mais importante por suprassumir as demais, sendo ela a instância distintiva das demais espécies, fundante do sentido da vida, tornando, assim, o indivíduo responsável e livre autor de sua existência, sendo a mais autêntica e atualizada forma do ser, uma vez que ela é o âmago da consciência humana.

O segundo passo foi apresentar a dimensão noética como a instância fundante do sentido da vida. Para Frankl, o fim último da existência humana está fora do indivíduo, apenas quando ele se desprende de si mesmo encontra um propósito que se desvela o sentido da vida, que por si só justifica a própria existência. Pode-se afirmar que o ser humano encontra sentido em um movimento eminentemente espiritual, a noodinâmica, instrumentalizada pela consciência e realizada em uma tarefa ou trabalho ao dar-se ao mundo, nas vivências e nos encontros ao abrir-se ao outro e no enfrentamento do sofrimento inevitável.

Em suma, o trabalho propôs-se a responder a seguinte questão problema: "O que é o ser humano em sua dimensão noética para Viktor Frankl?”. A essa pergunta a resposta é: para Frankl, a dimensão noética é a instância genuinamente humana, ou seja, tudo o que é próprio do ser humano (liberdade, responsabilidade, amor, consciência moral, criatividade, transcendência e intencionalidade) é originado dela, diferenciando-o, assim, dos outros animais.

Conclui-se, assim que, para Frankl, o ser humano é, em sua essência, um ser espiritual, livre e autodeterminado, capaz de refletir a respeito de si, amar e superar os maiores sofrimentos e por meio do sentido ressignificar sua própria existência.

As contribuições da teoria de Viktor Frankl são fundamentais para o desenvolvimento de uma psicologia que busca resgatar a autenticidade e o sentido da vida do paciente, atual e dinâmica. A logoterapia apresenta-se como uma alternativa terapêutica de retomada da esperança, da dignidade e da responsabilidade do ser humano ante sua própria existência.

\section{REFERÊNCIAS}

ARAÚJO, A. M. Estará em curso o desenvolvimento de um novo paradigma teórico para a evolução biológica? Pp. 1-28, in: MARTINS, Lilian Al-Chueyr Pereira; REGNER, Anna Carolina Krebs Pereira \& LORENZANO, Pablo (eds.). Ciências da vida: estudos filosóficos e históricos. Campinas: Associação de Filosofia e História da Ciência do Cone Sul (AFHIC), 2006. 
ARISTÓTELES. Metafísica. São Paulo: Edipro, 2006.

CARVALHO, O. de. O mínimo que você precisa saber para não ser um idiota [recurso eletrônico] /

Olavo de Carvalho; organização Felipe Moura Brasil. - 1. ed. - Rio de Janeiro: Record, 2013.

COMTE, A. Curso de filosofia positiva. 2. ed. São Paulo: Abril cultural, 1983.

DESCARTES, R. O discurso do método: para bem conduzir a própria razão e procurar a verdade nas ciências. São Paulo: Paulus, 2002.

DITTRICH, M. G. A criatividade do amor criante de Deus: uma vivência de cura espiritual na criação artística. São Leopoldo: Escola Superior de Teologia, 2008.

O corpo-criante: a chave para uma hermenêutica da obra de arte. Fragmentos de Cultura, Goiânia: Editora da Universidade Católica de Goiás, v. 14, n. 5, 2004.

DOOYEWEERD, H. A New Critique of Theoretical Thought. Ontario: Paideia Press, 1984.

FEYERABEND, P. Contra o método. 2. ed. São Paulo: UNESP, 2011.

FIZZOTTI, E. En las raíces de la logoterapia las raíces de la esperanza. Revista Mexicana de Logoterapia. v. 2 , p. $20-30,2014$.

FRAgatA, J. et al. Perspectivas da fenomenologia de Husserl. Coimbra: Centro de Estudos Fenomenológicos, 1965.

FRANKL, V; LAPIDE, P. A busca de Deus e questionamentos sobre o sentido. Petrópolis: Editora Vozes. Tradução de Márcia Neumann, 2014.

FRANKL, V. E. Psicoterapia: Uma casuística para médicos. São Paulo: E.P.U. 1976.

Fundamentos Antropológicos da Psicoterapia. Tradução de Renato Bittencourt. Rio de Janeiro: Zahar Editores, 1978.

A questão do sentido em psicoterapia. Campinas: Papirus, 1990.

. A psicoterapia na prática. Campinas: Papirus, 1991.

Logoterapia e análise existencial: textos de cinco décadas. Trad. Jonas Pereira dos Santos. Campinas: Editorial Psy II. 1995.

Psicoterapia e sentido da vida: fundamentos de logoterapia e análise existencial. Tradução de Alípio Maia de Castro. São Paulo: Quadrante, 2003.

A presença ignorada de Deus. 10 Ed. Trad. Walter O. Sclupp e Helga H. Reinhold. São Leopoldo, RS: Sinodal; Petrópolis, RJ: Vozes, 2007.

2008.

Em busca de sentido: um psicólogo no campo de concentração. Petrópolis: Editora Vozes,

O que não está escrito em meus livros: Memorias. São Paulo: É Realizações, 2010.

A vontade de sentido: fundamentos e aplicações da logoterapia. São Paulo: Paulus, 2011.

Sede de Sentido: Conceitos Básicos de logoterapia. 5. ed. São Paulo. Quadrante, 2011.

2012 .

Logoterapia e análise existencial: textos de seis décadas. Rio de Janeiro: Forense Universitária.

FREUD. S. Nova conf. XXXII: ansiedade e vida pulsional. Rio de Janeiro: Imago, 2006.

GUEDES, K. C.; GAUDÊNCIO, E. O. Trabalho e logoteoria: análise existencial da situação de desemprego.

Revista Logos \& Existência, v.1, p. 26-37. 2012. 
HAHNEMANN S. Organon da arte de curar. Ribeirão Preto: Museu de Homeopatia Abrahão Brickmann, 1995.

HARARI, Y. N. Sapiens: uma breve história da humanidade. Porto Alegre: Editora L\&PM, 2014.

HEGEL, G.W.F. Fenomenologia do espírito. Parte I. Trad. Paulo Meneses e Karl-Hetnz Efken. Petrópolis, Vozes, 1992.

KAUFFMAN, S. “O que é vida?”: Schrödinger estava certo? In: Murphy MP e O’Neill LAJ, organizadores. “O que é vida?” 50 anos depois. Especulações sobre o Futuro da biologia. São Paulo: Editora da UNESP, 1997.

KOYRÉ, A. Do mundo fechado ao universo infinito. Rio de Janeiro: Forense Universitária, 2006.

KROEFF, Paulo. Logoterapia: uma visão da psicoterapia. Rev. abordagem gestalt, Goiânia, v. 17, n. 1, p. 68-74, jun. 2011. Disponível em: < http://pepsic.bvsalud.org/scielo.php?script=sci_arttext\&pid=S1809 $68672011000100010 \& l n g=p t \& n r m=$ iso $>$. Acesso em: 12 nov. 2018.

LUKAS, E. Logoterapia: a força desafiadora do espírito. Tradução de José de Sá Porto. São Paulo: Edições Loyola, 1989.

- Histórias que curam... Porque dão sentido à vida. Petrópolis: Verus, 2005.

MATURANA, H.; VARELA, F.. A árvore do conhecimento: as bases biológicas do entendimento humano. São Paulo: Psy, 1995.

MARX, K.; ENGELS, F. A Ideologia Alemã. São Paulo: Bontempo, 2007.

NIETZSCHE, F. W. O nascimento da tragédia ou helenismo e pessimismo. Trad. de: J. Guinsburg. 2. ed. São Paulo: Companhia das Letras, 2001.

PAPAVERO, N. (org.) Fundamentos Práticos de Taxonomia Zoológica (Coleções, Bibliografia e Nomenclatura). 2. ed. São Paulo: Editora da Universidade Estadual Paulista, 1994.

PLATÃO. República. Tradução Maria Helena da Rocha Pereira. 9. ed. Lisboa: Fundação Calouste Gulbbenkian, 2001.

Diálogos: Teeteto, Cratilo. 3. ed. Belém: UFFA, 2001.

PETER, R.; Viktor Frankl: A antropologia como terapia. Trad. Thereza Christina Stummer São Paulo: Paulus, 1999.

SARTRE, J.P. O Existencialismo é um humanismo. 3. ed. Trad. Rita Correa Guedes. São Paulo, Abril Cultural. 1987

SCHULTZ, D. P.; SCHULTZ, S. E. História da psicologia história da psicologia moderna. 11. ed. São Paulo: Moderna Cultrix, 2016.

TROMBLEY, S. 50 pensadores que formaram o mundo moderno: perfis de cinquenta filósofos, cientistas, teóricos, políticos se sociais e líderes espirituais marcantes cujas ideia definiram a época em que vivemos. Tradução Breno Barreto. Rio de Janeiro: Leya. 2014.

XAUSA, I. A. M. A Psicologia do sentido da vida. 2. ed. Petrópolis: Vozes, 2012. 